\title{
KAHOOT! AND SOCRATIVE IN HIGHER EDUCATION: A COMPARATIVE STUDY
}

\author{
L. Chagas ${ }^{1}$, A. Pires ${ }^{2}$, S. Pais ${ }^{2}$ \\ ${ }^{1}$ Universidade de Lisboa (PORTUGAL) \\ ${ }^{2}$ Instituto Politécnico de Leiria (PORTIGAL)
}

\begin{abstract}
Technology brings new challenges and opportunities to higher education institutions, as it can promote learner-centered activities. Mobile devices such as smartphones are very popular among students and can easily engage them and promote motivation and active learning.

In this study, we investigate Tourism undergraduate students' perceptions on the use of mobile technology in the classroom, specifically two quiz makers in a comparative perspective: Kahoot! and Socrative. The purpose of this two-stage study is to identify and meet students' preferences, so as to design activities that can truly promote learning. The participants are Mathematics and English students from a Portuguese higher education institution.
\end{abstract}

At the first stage, in a preliminary survey, 33 students have identified their quiz preferences and most of them $(87,88 \%)$ selected Socrative as their favourite quiz maker. At the second stage, students were also inquired about their general perceptions and preferred features, such as collaborative mode, competition mode, self-paced mode or immediate feedback. Similar studies have shown that these tools can promote engagement, motivation, concentration and learning. Therefore, we hope to contribute to a better understanding of how technology can improve the learning process.

Keywords: Higher Education; students; web tools; educational technology; comparative analysis.

\section{INTRODUCTION}

The use of mobile technology is a promising trend in higher education. Several studies assessing students' attitudes towards this methodology show that the use of mobile devices in classes promotes motivation [1] [2]. Game-based learning is one of the approaches being adopted more frequently in learning environments that involve undergraduate students [3] [4]. Gee [5] argues that well-designed video games are learning machines and that they can be resorted to in formal educational contexts in order to enhance learning. The idea is that when students learn through games they become so motivated and engaged that they are not aware that they are learning while playing (Wang, 2015).

Having obtained good results regarding students' receptiveness to Kahoot! [7], the authors decided to resort to a different game-based learning tool, namely Socrative, in order to find if the highly positive results were influenced by the use of a specific platform, or by the method itself, as the participants in the study used both Kahoot! and Socrative.

Kahoot! was designed as a game, or as a game-based platform. Compared to other quiz-makers, Kahoot! focuses $100 \%$ on engaging and motivating students through a game experience where students compete. Research and feedback from teachers using Kahoot! have shown that the main difference between a game-based student response system (GSRS) like Kahoot! and a classical student response system (SRS) such as Socrative is the energy and engagement the gamification creates. In the case of Kahoot! this is achieved through the use of playful and colourful graphics and audio to increase engagement, as well as points and a scoreboard for competition [8].

Socrative shares many of the characteristics of Kahoot!, as both are web-based, do not require any special equipment, and offer game-based learning possibilities. However, unlike Kahoot!, Socrative provides games as add-ons to the main features. Socrative allows teachers to get feedback from the students through multiple choice questions, true or false statements, or short text answers. Socrative also offers the game SpaceRace where teams of students answer questions to move their rocket as fast as possible across the screen" [6]. 


\section{METHODOLOGY}

The participants of this study are 38 undergraduate students from a Portuguese higher education institution and the areas of study involved were English and Mathematics, in which students responded to a quiz after they concluded a syllabus topic. As there were three topics in total, the authors selected Kahoot! as the platform to be used in the first quiz and Socrative in the second one, so that students could select the tool they preferred for the third quiz.

Therefore, this study comprised two data collection stages in the first semester of the 2018/2019 academic year. At the first stage, after using both Kahoot! and Socrative in class, students were surveyed about the tool they preferred and stated their reasons, whereas at the second stage they responded to a new survey, by the end of the semester, regarding the features they found more important in both platforms.

In this study, data were collected by both quantitative and qualitative methods, as in both questionnaires students could share their opinion on these tools through open-ended questions. It is important to note that anonymity and confidentiality of participants were assured.

Statistical treatment of the data, specifically descriptive statistics (frequency distributions, mean, median and standard deviation), was performed using the Statistical Package for the Social Sciences (SPSS), version 25.0.

\subsection{Participants}

The participants of the study are Tourism undergraduate students who attended the curricular units of English for Tourism V, English III and Mathematics, as shown in the table below (Table 1).

Table 1. Distribution of participants.

\begin{tabular}{l|c|c|c}
\hline \hline & Participants & $\begin{array}{c}\text { Survey 1 } \\
\text { Respondents }\end{array}$ & $\begin{array}{c}\text { Survey 2 } \\
\text { Respondents }\end{array}$ \\
\hline English for Tourism V & 16 & 11 & 16 \\
\hline English III & 6 & 6 & 6 \\
\hline Mathematics & 16 & 16 & 13 \\
\hline \hline
\end{tabular}

\section{RESULTS}

\subsection{First survey}

At this initial data collection stage, the authors obtained a total of 33 responses. 17 students were attending the curricular unit of English and 16 were attending the curricular unit of Mathematics. Students were asked about which one of the online tools used in class they preferred for content revision at the end of a syllabus topic. 13 students attending the English curricular units said they preferred using Socrative $(76,47 \%)$, against 4 that selected Kahoot! as their favourite tool $(23,53 \%)$. In the case of Mathematics, $100 \%$ of the students (16 in total) chose Socrative as their tool of choice for content reviewing. These results are shown in the figure below (Figure 1). 


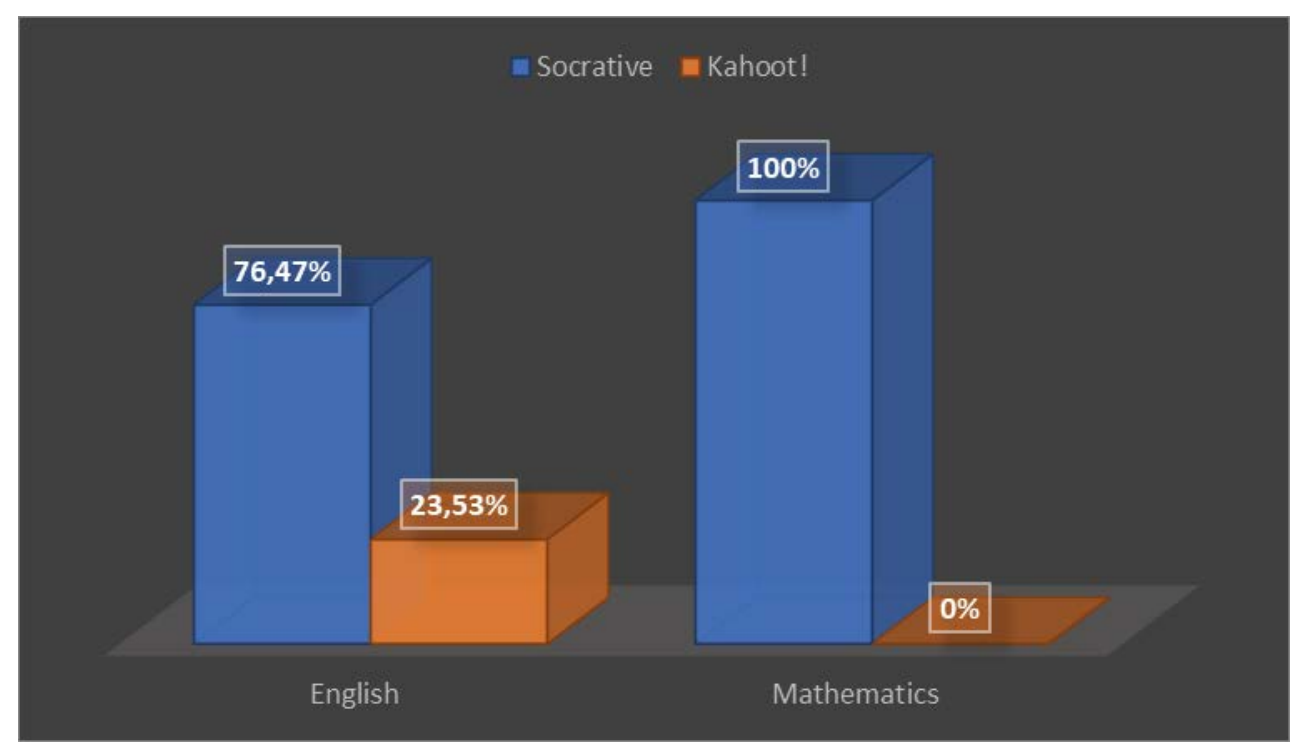

Figure 1 - Students' preferences regarding the use of Kahoot! and Socrative according to area of study.

Analysing the results in total, only 4 students $(12,12 \%)$ selected Kahoot! as their favourite platform, whereas $29(87,88 \%)$ preferred Socrative for content reviewing at the end of a syllabus topic. These results are shown in the figure below (Figure 2).

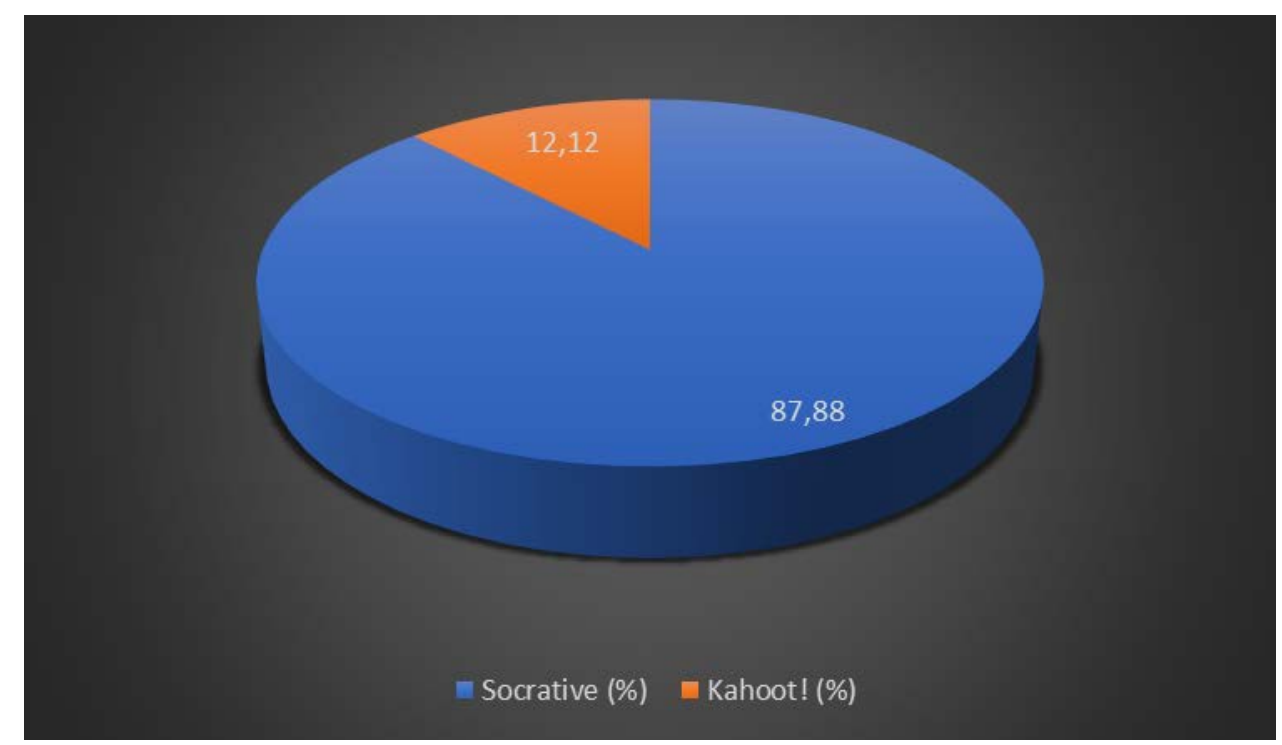

Figure 2 - Students' preferences regarding the use of Kahoot! and Socrative.

When selecting their favourite quiz maker, the students could also state their reasons in an openended question. In a total of 11 written responses, only one mentioned Kahoot! as the favourite quiz maker, mentioning the fact that it is easier to use, more practical and accessible. Regarding Socrative, seven students referred to the advantage of having no time limit for answering questions when using this tool, which allowed them to respond at their own pace. Besides this feature, two students mentioned the possibility of having short text answers as an important asset, one of them identified immediate feedback as a relevant attribute and another one referred to the visual aspect of the tool, considering it very professional and "clean". Finally, another student considered Socrative to be more practical to play than Kahoot!.

\subsection{Second survey}

At the second stage, a total of 35 students responded to the questionnaire, which was divided into four parts, that included (i) personal information, (ii) importance of the use of mobile learning in the 
classroom, specifically the importance of quiz makers such as Kahoot! and Socrative (iii) the main features and potential usefulness of these tools and (iv) open-ended question.

General results regarding the importance of the use of mobile learning in the classroom show a positive attitude towards the integration of mobile technology and the use of online quizzes in class. More specifically, we can say that most students believe that mobile technology contributes to active learning $(m=4,54, s d=, 817)$ and that quizzes help them revising content $(m=4,46, s d=, 817)$. The item with the lowest score is the one regarding the motivation to learn induced by quiz makers $(m=$ $4,11, s d=1,051$ ), but one should note the high value of standard deviation, which shows that students' opinions are not consensual (Table 2). Despite being the lowest score, the mean is fairly high. Another important result in our perspective has to do with the use of technology in other areas of study. When asked if they would like mobile technology to be used in other curricular units, students' results were highly favourable $(m=4,20, s d=, 964)$.

Table 2. Results of individual survey regarding the importance of mobile learning and quiz makers.

\begin{tabular}{l|c|c|c}
\hline \hline & Mean (1 to 5) & Std Dev & Median \\
\hline $\begin{array}{l}1 \text { - I believe the use of mobile technology (e.g. } \\
\text { smartphones) is useful in this Curricular Unit (CU) }\end{array}$ & 4.26 & 0.886 & 4 \\
\hline $\begin{array}{l}2 \text { - I would like mobile technology to be used in } \\
\text { other CUs. }\end{array}$ & 4.20 & 0.964 & 4 \\
\hline $\begin{array}{l}3 \text { - Mobile technology contributes to a more active } \\
\text { learning }\end{array}$ & 4.54 & 0.817 & 5 \\
\hline $\begin{array}{l}4 \text { - I believe quizzes are important in the CU I } \\
\text { attend }\end{array}$ & 4.20 & 0.833 & 4 \\
\hline 5 - Quizzes are useful for content revision. & 4.46 & 0.817 & 5 \\
\hline 6 - Quizzes motivate me to learn. & 4.11 & 1.051 & 4 \\
\hline 7 - I would like to do more quizzes in class. & 4.31 & 0.832 & 4 \\
\hline \hline
\end{tabular}

As far as the main features and potential usefulness of these tools are concerned, access to "immediate feedback" obtained the highest mean score $(m=4,74$, sd $=, 611)$, followed by "content revision" $(\mathrm{m}=4.51, \mathrm{sd}=0.781)$. The lowest mean score refers to the possibility of using a quiz for "homework" $(m=4,51, \mathrm{sd}=0,781)$. The results are shown in Table 3.

Table 3. Results of individual survey regarding the potential usefulness and main features of quiz makers

\begin{tabular}{l|c|c|c}
\hline \hline & Mean (1 to 5) & Std Dev & Median \\
\hline 1- Introducing new themes & 3.89 & 1.132 & 4 \\
\hline 2- Content revision & 4.51 & 0.781 & 5 \\
\hline 3- Homework & 3.34 & 1.371 & 3 \\
\hline 4- Competition mode & 3.97 & 1.098 & 4 \\
\hline 5- Collaborative mode & 3.94 & 0.968 & 4 \\
\hline 6- Self-paced mode & 4.11 & 1.022 & 4 \\
\hline 7- Immediate feedback & 4.74 & 0.611 & 5 \\
\hline \hline
\end{tabular}

In the open-ended question, concerning the opinion on the usefulness of mobile technology and/or online quizzes, only two students answered, mentioning two very different perspectives on the theme. One of them referred to the importance of team spirit and healthy competition, which motivates them to study, whereas another one stresses the fact that this type of activity can cause a lot of agitation in class. 


\section{CONCLUSIONS}

Regarding the first survey, most students preferred using Socrative in class for content reviewing. These results differ from those of Bicen and Kocakoyun [9] who investigated students' most preferred application among four examples, namely Kahoot!, ClassDojo, Classcraft and Socrative. In this case, $39 \%$ of students considered Kahoot! to be their preferred app, whereas only $12 \%$ selected Socrative as their favourite app. As Socrative was being used in class for the first time, this might have influenced students' preferences. As Baker, D'Mello, Rodrigo and Graesser [10] argue, even though these gamebased learning tools spark immediate enthusiasm in the class, they may, in time, lead to boredom and disinterest. It is important that GSRSs keep students engaged for repetitive usage over time.

Results from survey two indicate that most students consider mobile technology to contribute to a more active learning. Furthermore, immediate feedback provided by game-based learning tools is also a feature highlighted by the students as very important. Both results are in consonance with the findings described by Ismali and Mohammad [11] regarding the use of Kahoot and by Dervan [12], who reports on results concerning Socrative.

In conclusion, mobile technology can bring endless learning opportunities due to its "almost ubiquitous availability" as Crompton and Burke [13] claim. Consequently, it is essential to keep investigating the use of digital devices in the classroom in order to find new ways of improving learning.

\section{REFERENCES}

[1] M. Al-Emran, H. M. Elsherif, and K. Shaalan, "Investigating attitudes towards the use of mobile learning in higher education," Computers in Human Behavior, vol. 56, pp. 93-102, 2016.

[2] S. A. Licorish, H. E. Owen, B. Daniel, and J. L. George, "Students' perception of Kahoot!'s influence on teaching and learning," Research and Practice in Technology Enhanced Learning, vol. 13, no. 1, Jul. 2018.

[3] J. Hamari, D. J. Shernoff, E. Rowe, B. Coller, J. Asbell-Clarke, and T. Edwards, "Challenging games help students learn: An empirical study on engagement, flow and immersion in gamebased learning," Computers in Human Behavior, vol. 54, pp. 170-179, 2016. doi: 10.1016/j.chb.2015.07.045

[4] B. E. Wiggins. "An overview and study on the use of games, simulations, and gamification in higher education". International Journal of Game-Based Learning (IJGBL), 6(1), pp. 18-29, 2016. doi: 10.4018/ijgbl.2016010102

[5] J. P. Gee. (2013). “Games for learning”. Educational Horizons, 91(4), 16-20.

[6] A. I. Wang. "The wear out effect of a game-based student response system". Computers \& Education, 82, pp. 217-227, 2015. doi: 10.1016/j.compedu.2014.11.004

[7] S. Pais, A. Pires, L. Chagas. "Enhancing student motivation with Kahoot! - A case study in English and Mathematics". Edulearn18 Proceedings, pp. 5518-5522, 2018. doi: 10.21125/edulearn.2018.1328

[8] A. I. Wang \& A. Lieberoth. "The effect of points and audio on concentration, engagement, enjoyment, learning, motivation, and classroom dynamics using Kahoot". In European Conference on Games Based Learning (p. 738). Academic Conferences International Limited, 2016.

[9] H. Bicen \& S. Kocakoyun. "Determination of university students' most preferred mobile application for gamification". World Journal on Educational Technology: Current Issues. 9(1), pp. 18-23, 2017. Doi: $10.18844 /$ wjet.v9i1.641

[10] R. S. J. d. Baker, S. K. D'Mello, M. M. T. Rodrigo, and A. C. Graesser, "Better to be frustrated than bored: The incidence, persistence, and impact of learners' cognitive-affective states during interactions with three different computer-based learning environments," International Journal of Human-Computer Studies, vol. 68, no. 4, pp. 223-241, 2010. doi:10.1016/j.ijhcs.2009.12.003

[11] A.-A. Ismail and J. A.-M. Mohammad, "Kahoot: A Promising Tool for Formative Assessment in Medical Education," Education in Medicine Journal, vol. 9, no. 2, pp. 19-26, 2017. doi:10.21315/ eimj2017.9.2.2 
[12] P. Dervan. "Increasing in-class student engagement using Socrative (an online Student Response System)". AISHE-J: The All Ireland Journal of Teaching and Learning in Higher Education, 6(3), pp. 1801-1813, 2014.

[13] H. Crompton and D. Burke, "The use of mobile learning in higher education: A systematic review," Computers \& Education, vol. 123, pp. 53-64, Aug. 2018. doi:10.1016/j.compedu.2018.04.007 